\title{
Familial hypercholesterolemia: clinical pearls
}

\begin{abstract}
Familial hypercholesterolemia is an important cause of premature cardiovascular disease. A defect in low-density lipoprotein (LDL) metabolism results in extremely elevated levels of LDL-cholesterol. Although it was one of the most common genetic disorders, it is frequently underdiagnosed or inappropriately treated. Current advances in LDL lowering therapies have made a great promise in treating familial hypercholesterolemia. Early recognition and optimal control of LDL levels are crucial in preventing its atherosclerotic burden. A multi-disciplinary approach is needed to provide optimal care for patients with familial hypercholesterolemia. In this clinical paper, we outline the current knowledge about screening, diagnosis, and management of familial hypercholesterolemia.
\end{abstract}

Keywords: familial hypercholesterolemia, inherited dyslipidemia, atheroscelorsis, cardiovascular disease, premature myocardial infarction, primary prevention
Volume 12 Issue 5 - 2019

\author{
Yousif M Hydoub,' Seema Nour ${ }^{2}$ \\ 'Department of medicine, Mafraq Hospital, United Arab \\ Emirates \\ ${ }^{2}$ Department of cardiac sciences, Sheikh Khalifa Medical City, \\ United Arab Emirates
}

Correspondence: Yousif M Hydoub, Mafraq Hospital, Bani Yas, Abu Dhabi, United Arab Emirates, Email yomohamed@seha.ae

Received: October 02, 2019 | Published: October II, 2019
Abbreviations: FH, familial hypercholesterolemia; LDL, lowdensity lipoprotein; CV, cardiovascular; ApoB-100, apolipoprotein B-100; PCSK9, proprotein convertase subtilisin/kexin type 9

\section{Introduction}

Familial hypercholesterolemia $(\mathrm{FH})$ is an inherited disorder that results in a disturbance in the metabolism of low-density lipoprotein cholesterol (LDL). It affects both adults and children, depending on genotypic features. FH, especially if untreated, results in devastating cardiovascular $(\mathrm{CV})$ morbidity and mortality. ${ }^{1,2}$

\section{Etiology}

$\mathrm{FH}$, in its commonest type, is due to an autosomal dominant defect in the genes encoding for proteins involved in LDL metabolism. There are autosomal recessive variants, but these are much less common. ${ }^{3}$ Patients can have a homozygous or a heterozygous defect, which will determine the severity of the disease and the age of onset of $\mathrm{CV}$ disease manifestations. The three main genetic defects that lead to FH are defects in the LDL receptor gene (most common), apolipoprotein B-100 (ApoB-100) gene ${ }^{4}$, and proprotein convertase subtilisin/Kexin type 9 (PCSK9) gene. ${ }^{5}$ These three mutations account for 60 to 80 percent of patients with definite $\mathrm{FH}^{6}{ }^{6}$ Other mutations, like the signaltransducing adaptor family member 1 (STAP1) gene mutation, have been reported to be associated with $\mathrm{FH}^{7}$

\section{Epidemiology}

The prevalence of FH varies depending on the population studied and the criteria used for diagnosis. Homozygous FH is relatively rare with a reported prevalence of 1 in 300,000 individuals. ${ }^{8}$ Homozygous FH is much more common, yet underdiagnosed, with a prevalence of 1 in 250 to 1 in 500 individuals. ${ }^{9,10}$ The prevalence is higher in obese individuals. There is no reported sex predilection, but a variation among races with African Americans having the highest reported prevalence in the NHANES study.

\section{Pathophysiology}

There are multiple genetic mutations that lead to the phenotypic features of FH. The end-result in all pathways is the dysfunctional binding of LDL receptors to the LDL cholesterol, thereby decreasing the uptake and destruction of LDL cholesterol in the liver and the resultant rise in serum LDL levels. One of the most common and wellstudied mutations is due to numerous "loss of function" mutations in the gene encoding for the LDL receptor protein on chromosome $19 .{ }^{11}$ A less common mutation is one that encodes for ApoB-100, a protein on the LDL receptor that binds to the LDL cholesterol. In the last twenty years, or so, a new "gain of function" mutation in the PCSK9 gene was found to be highly associated with familial hypercholesterolemia. ${ }^{12-14}$ PCSK9 proteins binds to the LDL receptor, which results in internalization of the LDL receptor, thereby reducing the number of expressed receptors available to bind LDL cholesterol.

\section{Symptoms and signs}

Homozygous FH typically manifests in childhood. Findings include xanthelasmas and xanthomas in the skin, joints, ears, tendons, and other sites. Patients with heterozygous FH are usually asymptomatic, but xanthomas start to develop by the third decade of life. Arcus cornealis before the age of 45 is also common. Symptoms of coronary heart disease (e.g. angina, myocardial infarction, and heart failure), aortic stenosis, cerebrovascular disease, and peripheral arterial disease are common manifestations.

\section{Evaluation}

\section{Diagnostic criteria}

The two most commonly used criteria for evaluation and diagnosis of FH are the Dutch lipid clinic criteria and the Simon Broome criteria. $^{15,16}$ Both incorporate LDL levels, presence of xanthomas, presence of a genetic mutation or family history of $\mathrm{FH}$, premature cardiovascular events, tendinous xanthomas and/or arcus cornealis and elevated LDL levels in young ages. The Dutch lipid clinic criteria categorize patients into definite, probable, possible or unlikely $\mathrm{FH}$, while the Simon Broome classifies patients as definite or possible. Having only an LDL level of $330 \mathrm{mg} / \mathrm{dl}$ or more, or a mutation in the LDL receptor, ApB-100 or the PCSK9 gene will earn a diagnosis of probable $\mathrm{FH}$, based on the Dutch lipid clinic criteria. If a patient has any of the additional factors of the Dutch lipid clinic, on top of the gene mutation or the above-mentioned LDL level, the diagnosis 
becomes definite FH. Based on the Simon Broom criteria, a diagnosis of definite FH requires an LDL level of at least $155 \mathrm{mg} / \mathrm{dl}$ and a gene mutation or tendinous xanthomas in the patient or first- or seconddegree relatives.

\section{Cascade screening}

Because $\mathrm{FH}$ is a common and frequently unrecognized genetic disorder, cascade screening is recommended. ${ }^{17,18}$ Once a patient is diagnosed with FH. All first-degree relatives should be screened. If a new case of FH is diagnosed during screening, all first-degree relatives of the new proband should be screened and so forth. Screening methods include, preferably, genetic testing and/or lipid tests.

\section{Treatment}

\section{Approach to therapy}

A holistic approach should be sought in the treatment of FH. Besides lowering LDL levels, control of the patient's lifestyle risk and other modifiable risk factors of coronary heart disease is essential in reducing $\mathrm{CV}$ morbidity and mortality in patients with FH. Setting a suitable target LDL level is difficult, as patients with FH present with varying degrees of elevated LDL levels. Most guidelines recommend a reduction of $50 \%$ or more of the initial untreated LDL level, in patients with FH. ${ }^{19,20}$ Some guidelines consider patients with prior coronary heart disease or concomitant diabetes are considered high risk and are recommended to have an LDL level below $70 \mathrm{mg} / \mathrm{dL}$, while patients without prior coronary heart disease or diabetes are considered low-moderate risk and have recommended target LDL level below $100 \mathrm{mg} / \mathrm{dL}$. LDL levels should be checked every 2-3 months, while on treatment, to adjust drug therapies accordingly.

\section{Drug therapies}

Statins are the gold standard therapy for FH. All guidelines recommend statins as first-line drugs for patients with $\mathrm{FH}$, with a goal of reaching maximally tolerated doses. ${ }^{21}$ The effect of statins has been well studied and most randomized clinical trials observed a reduction of around 50 percent of the initial untreated LDL levels, as well as a reduction in cardiovascular events. ${ }^{22-24}$ Unfortunately, a large number of patients with $\mathrm{FH}$, on maximally tolerated statins alone, either do not show this level of reduction in LDL levels, or they do not reach their goal LDL levels, even with a 50 percent reduction, because their initial LDL levels are so high. Second-line therapies include ezetimibe and PCSK9 inhibitors. Ezetimibe has been showing to add an extra 10 to 30 percent reduction in LDL levels for patients on maximally tolerated statins. ${ }^{25,26}$ Currently, ezetimibe is the drug of choice as second line in most guidelines. ${ }^{27,28}$ PCSK9 inhibitors have shown a great reduction in LDL levels and cardiovascular outcomes in different randomized clinical trials. ${ }^{29,30}$ In those trials, PCKS9 inhibitors lowered LDL levels by 50 to 60 percent. While exhibiting higher efficacy than ezetimibe, the use of PCSK9 inhibitors is limited by their high costs and the reluctance of insurance companies to approve their use. ${ }^{31}$ Hence, PCSK9 inhibitors can be used as second or third-line drugs for patients with FH. Fourth line therapies include mipomersen, lomitapide, LDL apheresis, ileal bypass surgery, and liver transplantation. ${ }^{32-35}$ These are usually reserved if the LDL does not reach the target level with the use of statins, ezetimibe and PCSK9 inhibitors.

\section{Prognosis}

Patients with homozygous FH have a poor prognosis. They usually die before the third decades of life from CV events.36 Patients with heterozygous FH are usually asymptomatic until the third decade of life. After that, their risk of premature cardiovascular events increases exponentially.

\section{Consultations}

Consultation with a lipid specialist is recommended whenever LDL cholesterol is above goal, with maximally tolerated statins and ezetimibe. ${ }^{37}$

\section{Clinical pearls}

a. FH is a common cause of premature cardiovascular events in children and adults

b. Various diagnostic criteria of FH are available online and can help direct further workup

c. Heterozygous FH is under recognized and commonly treated sub-optimally

d. Cascade screening of first-degree relatives of patients with FH is essential in primary prevention of $\mathrm{CV}$ events

e. Referral to a lipid specialist can help optimize the control of LDL hypercholesterolemia in patients with FH

\section{Acknowledgments}

None.

\section{Conflicts of interest}

None declared.

\section{References}

1. Nordestgaard B, Chapman M, Humphries S. Familial hypercholesterolaemia is underdiagnosed and undertreated in the general population: guidance for clinicians to prevent coronary heart disease. Consensus Statement of the European Atherosclerosis Society. Eur Heart J. 2013;34(45):3478-3490a.

2. Pérez de Isla L, Alonso R, Mata $\mathrm{N}$, et al. Coronary Heart Disease, Peripheral Arterial Disease, and Stroke in Familial Hypercholesterolaemia: Insights From the SAFEHEART Registry (Spanish Familial Hypercholesterolaemia Cohort Study). Arterioscler Thromb Vasc Biol. 2016;36(9):2004-2010.

3. Zuliani G, Arca M, Signore A, et al. Characterization of a new form of inherited hypercholesterolemia: familial recessive hypercholesterolemia. Arterioscler Thromb Vasc Biol. 1999;19(3):802-809.

4. Fernandez-Higuero JA, Etxebarria A, Benito-Vicente A, et al. Structural analysis of APOB variants, p. (Arg3527Gln), p. (Arg1164 Thr) and p. (Gln4494del), causing familial hypercholesterolaemia provides novel insights into variant pathogenicity. Sci Rep. 2015;5:18184.

5. Maxwell KN, Fisher EA, Breslow JL. Overexpression of PCSK9 accelerates the degradation of the LDLR in a postendoplasmic reticulum compartment. Proc Natl Acad Sci USA. 2005;102(6):2069-2074.

6. Knowles JW, Rader DJ, Khoury MJ. Cascade Screening for Familial Hypercholesterolemia and the Use of Genetic Testing. JAMA. 2017;318(4):381-382.

7. Fouchier SW, Dallinga-Thie GM, Meijers JCM, et al. Mutations in STAP1 are associated with autosomal dominant hypercholesterolemia. Circ Res. 2014;115(6):552-555.

8. Sjouke B, Kusters DM, Kindt I, et al. Homozygous autosomal dominant hypercholesterolaemia in the Netherlands: prevalence, genotype-phenotype relationship, and clinical outcome. Eur Heart $J$. 2015;36(9):560-565. 
9. Austin MA, HutterCM,Zimmern RL, etal.Familial hypercholesterolemia and coronary heart disease: a HuGE association review. Am J Epidemiol. 2004;160(5):421-429.

10. De Ferranti SD, Rodday AM, Mendelson MM, et al. Prevalence of Familial Hypercholesterolemia in the 1999 to 2012 United States National Health and Nutrition Examination Surveys (NHANES). Circulation. 2016;133(11):1067-1072.

11. Hobbs HH, Russell DW, Brown MS, et al. The LDL receptor locus in familial hypercholesterolemia: mutational analysis of a membrane protein. Annu Rev Genet. 1990;24:133-170.

12. Varret M, Rabès JP, Saint-Jore B, et al. A third major locus for autosoma dominant hypercholesterolemia maps to 1p34.1-p32. Am J Hum Genet. 1999;64(5):1378-1387.

13. Abifadel M, Varret M, Rabès JP, et al. Mutations in PCSK9 cause autosomal dominant hypercholesterolemia. Nat Genet. 2003;34(2):154 156.

14. Abifadel M, Guerin M, Benjannet $\mathrm{S}$, et al. Identification and characterization of new gain-of-function mutations in the PCSK9 gene responsible for autosomal dominant hypercholesterolemia Atherosclerosis. 2012;223(2):394-400.

15. WHO Human Genetics Programme. Familial hypercholesterolaemia (FH): report of a second WHO consultation, Geneva, 4 September 1998 Geneva: World Health Organization; 1999.

16. Wierzbicki AS, Humphries SE, Minhas R, et al. Familial hypercholesterolaemia: summary of NICE guidance. $B M J$. 2008;337:a1095.

17. Klančar G, Grošelj U, Kovač J, et al. Universal Screening for Familial Hypercholesterolemia in Children. $J$ Am Coll Cardiol. 2015;66(11):1250-1257.

18. Galema-Boers JMH, Versmissen J, Roeters van Lennep HWO, et al. Cascade screening of familial hypercholesterolemia must go on Atherosclerosis. 2015;242(2):415-417.

19. Writing Committee, Lloyd-Jones DM, Morris PB, et al. 2016 ACC Expert Consensus Decision Pathway on the Role of Non-Statin Therapies for LDL-Cholesterol Lowering in the Management of Atherosclerotic Cardiovascular Disease Risk: A Report of the American College of Cardiology Task Force on Clinical Expert Consensus Documents. J Am Coll Cardiol. 2016;68(1):92-125.

20. Goldberg AC, Hopkins PN, Toth PP, et al. Familial hypercholesterolemia screening, diagnosis and management of pediatric and adult patients: clinical guidance from the National Lipid Association Expert Panel on Familial Hypercholesterolemia. J Clin Lipidol. 2011;5(3):133-140.

21. Stone NJ, Robinson JG, Lichtenstein AH, et al. 2013 ACC/AHA guideline on the treatment of blood cholesterol to reduce atherosclerotic cardiovascular risk in adults: a report of the American College of Cardiology/American Heart Association Task Force on Practice Guidelines. J Am Coll Cardiol. 2014;63(25 Pt B):2889-2934.

22. Jones P, Kafonek S, Laurora I, et al. Comparative dose efficacy study of atorvastatin versus simvastatin, pravastatin, lovastatin, and fluvastatin in patients with hypercholesterolemia (the CURVES study). Am J Cardiol. 1998;81(5):582-587.

23. Smilde TJ, van Wissen S, Wollersheim H, et al. Effect of aggressive versus conventional lipid lowering on atherosclerosis progression in familial hypercholesterolaemia (ASAP): a prospective, randomised, double-blind trial. Lancet. 2001;357(9256):577-581.
24. deGoma EM, Ahmad ZS, O'Brien EC, et al. Treatment Gaps in Adults With Heterozygous Familial Hypercholesterolemia in the United States: Data From the CASCADE-FH Registry. Circ Cardiovasc Genet. 2016;9(3):240-249.

25. Murphy SA, Cannon CP, Blazing MA, et al. Reduction in Tota Cardiovascular Events With Ezetimibe/Simvastatin Post-Acute Coronary Syndrome: The IMPROVE-IT Trial. J Am Coll Cardiol. 2016;67(4):353-361

26. Kastelein JJP, Akdim F, Stroes ESG, et al. Simvastatin with or without ezetimibe in familial hypercholesterolemia. $N$ Engl J Med 2008;358(14):1431-1443.

27. Grundy SM, Stone NJ, Bailey AL, et al. 2018 AHA/ACC/AACVPR/ AAPA/ABC/ACPM/ADA/AGS/APhA/ASPC/NLA/PCNA Guideline on the Management of Blood Cholesterol: A Report of the American College of Cardiology/American Heart Association Task Force on Clinical Practice Guidelines. J Am Coll Cardiol. 2019;73(24):e285e350.

28. Cuchel M, Bruckert E, Ginsberg HN, et al. Homozygous familial hypercholesterolaemia: new insights and guidance for clinicians to improve detection and clinical management. A position paper from the Consensus Panel on Familial Hypercholesterolaemia of the European Atherosclerosis Society. Eur Heart J. 2014;35(32):2146-2457.

29. Sabatine MS, Giugliano RP, Keech AC, et al. Evolocumab and Clinical Outcomes in Patients with Cardiovascular Disease. $N$ Engl $\mathrm{J}$ Med. 2017;376(18):1713-1722.

30. Robinson JG, Farnier M, Krempf M, et al. Efficacy and safety of alirocumab in reducing lipids and cardiovascular events. $N$ Engl J Med. 2015;372(16):1489-1499.

31. Arrieta A, Hong JC, Khera R, et al. Updated Cost-effectiveness Assessments of PCSK9 Inhibitors from the Perspectives of the Health System and Private Payers: Insights Derived From the FOURIER Trial. JAMA Cardiol. 2017;2(12):1369-1374

32. Duell PB, Santos RD, Kirwan BA, et al. Long-term mipomersen treatment is associated with a reduction in cardiovascular events in patients with familial hypercholesterolemia. $J$ Clin Lipidol. 2016;10(4):1011-1021.

33. Cuchel M, Meagher EA, du Toit Theron H, et al. Efficacy and safety of a microsomal triglyceride transfer protein inhibitor in patients with homozygous familial hypercholesterolaemia: a single-arm, open-label, phase 3 study. Lancet. 2013;381(9860):40-46.

34. Buchwald H, Campos CT. Partial ileal bypass in the therapy of familial hypercholesterolemia. The POSCH Group. Beitr Infusionsther. 1988;23:47-60.

35. Matsuzaki M, Hiramori K, Imaizumi T, et al. Intravascular ultrasound evaluation of coronary plaque regression by low density lipoproteinapheresis in familial hypercholesterolemia: the Low Density Lipoprotein-Apheresis Coronary Morphology and Reserve Trial (LACMART). J Am Coll Cardiol. 2002;40(2):220-227.

36. Cuchel M, Bruckert E, Ginsberg HN, et al. Homozygous familial hypercholesterolaemia: new insights and guidance for clinicians to improve detection and clinical management. A position paper from the Consensus Panel on Familial Hypercholesterolaemia of the European Atherosclerosis Society. Eur Heart J. 2014;35(32):2146-2157.

37. Bouhairie VE, Goldberg AC. Familial hypercholesterolemia. Cardiol Clin. 2015;33(2):169-179. 